\title{
Lactulose: an effective preventive and therapeutic option for ischemic stroke by production of hydrogen
}

\author{
Xiao Chen ${ }^{1}$, Xiao Zhai ${ }^{2}$, Zhimin Kang $^{3}$ and Xuejun Sun ${ }^{3 *}$
}

\begin{abstract}
Lactulose, a synthetic sugar not able to be digested and absorbed by human beings, is widely used to treat constipation and hepatic encephalopathy clinically. Through fermentation by the bacteria in the gastrointestinal tract, lactulose can produce considerable amount of hydrogen, which is protective for ischemic stroke as a unique antioxidant. We propose that lactulose can induce the production of endogenous hydrogen that in turn reduces oxidative stress and ameliorate the stroke damage in human beings.
\end{abstract}

Keywords: lactulose, hydrogen, ischemia/reperfusion, antioxidant, stroke

\section{Introduction}

Currently stroke is the second leading cause of death in the Western world, ranking after heart diseases and before cancer [1], causing $10 \%$ of deaths worldwide [2]. It is estimated that stroke could soon be the most common cause of death worldwide [3]. An ischemic stroke can be due to ischemia (lack of blood flow) caused by blockage (thrombosis, arterial embolism), which may lead to rapidly developing loss of brain functions as a result of disturbance in the blood supply to the brain [4]. Stroke can affect patients physically, mentally, emotionally, or a combination of the three and bring heavy burdens to society.

Ischemia induces production of reactive oxygen species (ROS), which can react with and damage a number of cellular and extracellular elements. Evidence has accumulated showing that ROS are involved in cerebral ischemia and reperfusion. During cerebral ischemia, cerebral blood flow was partially or completely cut off in brain regions supplied by the occluded vessels. Reoxygenation due to spontaneous or thrombolytic reperfusion offers oxygen as a substrate for a number of enzymatic oxidation, constantly generating ROS like superoxide anion radicals $\left(\mathrm{O}_{2} \cdot-\right)$ and hydrogen peroxide

\footnotetext{
* Correspondence: sunxjk@hotmail.com

${ }^{3}$ Department of Diving Medicine, Faculty of Naval Medicine, Second Military Medical University, Shanghai 200433, PR China

Full list of author information is available at the end of the article
}

$\left(\mathrm{H}_{2} \mathrm{O}_{2}\right)$ [5]. ROS are known to be able to result in macromolecular damages including lipid peroxidation, protein oxidation, and DNA oxidation, which result in ischemic brain injury [6]. Clinically, a number of recent studies have revealed that stroke and oxidative stress are closely related and excess oxidative stress may have deleterious effects on clinical outcome in acute ischemic stroke $[7,8]$. Therefore, antioxidants have been considered in prevention and treatment of stroke and certain agents with antioxidative effects did have neuroprotective effects [9].

\section{Molecular hydrogen $\left(\mathrm{H}_{2}\right)$ serves as a novel inflammation suppressor}

In recent years, experimental evidences have documented that without influencing other less potent ROS, important in intracellular signaling, molecular hydrogen possesses the ability to selectively neutralize $\mathrm{ONOO}^{-}$ and $\bullet \mathrm{OH}$, the most cytotoxic ROS, which can damage cellular macromolecules aggressively and indiscriminately. Thus, hydrogen can protect cells from oxidative stress injuries [10]. Therapeutic effects of hydrogen gas and hydrogen-rich saline have been experimentally confirmed in a number of studies, including hypoxia $[11,12]$, ischemia-reperfusion injuries in various tissues and organs [13-18], and other injuries related to oxidative stress. Especially in brain ischemia, our previous research has demonstrated that hydrogen administration 
after hypoxia appeared to provide brain protection via inhibition of neuronal apoptosis in neonatal hypoxiaischemia rat model [19]. Another study reported that $2.1 \%$ hydrogen-supplemented room air ventilation would preserve cerebrovascular reactivity $(\mathrm{CR})$ and brain morphology after asphyxia/reventilation $(A / R)$ in newborn pigs [20]. For transient cerebral ischemia, hydrogen also showed significant protective effects [21]. Several studies have demonstrated the neuroprotective effects of molecular hydrogen. Interestingly enough, even for some chronic neurodegenerative diseases, like the Alzheimer's disease [22] and Parkinson disease [23,24], hydrogen showed certain protective effects.

As a novel antioxidant, hydrogen possesses a number of advantages. (1) Due to its high permeability, hydrogen can easily penetrate biomembranes and diffuse into the cytosol, mitochondria and nucleus. (2) It is nontoxic to the organisms, which has been proven by hyperbaric diving study for decades. (3) Due to its selectivity as an antioxidant, hydrogen has less impact on other less active but very important ROS within the cells.

\section{Endogenous hydrogen is effective for alleviating oxidative stress}

For therapeutic purposes, whether inhalation of hydrogen gas or injection or drinking of hydrogen-rich saline have unavoidable inconvenience. Hydrogen gas is highly flammable and explosive, thus being very dangerous. The effects of hydrogen-rich saline are not so ideally maintained. Therefore, frequent administration is required. Couldn't it be better if there is a way leading to persistent hydrogen generation under control? Endogenous hydrogen may give a perfect answer.

Early in 1969, a study published in the New England Journal of Medicine showed that endogenous hydrogen existed within human beings [25]. Studies have revealed that bacteria in the large intestine could generate endogenous hydrogen through anaerobic metabolism in human beings and animals [26]. Previously, the biologic effects of this little amount of hydrogen were often neglected, because studies have shown that the hydrogen level in normal terminal breath is about 5-10 ppm. However, in patients with lactose intolerance and bacterial disorders, the level may reach more than $90 \mathrm{ppm}$ [27]. Hydrogen concentration has been measured in different organs of normal mice. The results showed that hydrogen level was very high in the large intestine, spleen, liver and gastric mucosa [28]. In the liver it reached to $42 \mu \mathrm{M}$, and in the large intestine and spleen it was even higher. A research on PC12 cells showed that a concentration of $25 \mu \mathrm{M}$ of hydrogen in the medium would display a significant anti-oxidation effect [10]. These results indicated that endogenous hydrogen generated might have important biological effects.
Some of the recent findings further imply the potential therapeutic effects of endogenous hydrogen. Acarbose, which inhibits glucose absorption and often causes abdominal distention in diabetes mellitus treatment, shows an amazing cardiac protective effect. One of the main gases generated, which cause the abdominal distention, is hydrogen [29]. Oral administration of curcumin could also promote the production of endogenous hydrogen, which may be one of the mechanisms for curcumin treatment of some diseases [30]. Moreover, it is reported that oral administration of bacteria producing hydrogen gas can prevent Con A-induced hepatitis. And after antibiotic treatment, the protective effect amazingly disappeared, indicating that hydrogen produced by intestinal bacteria was the key for therapeutic effects [31].

Since hydrogen production in man is primarily dependent on the delivery of ingested, fermentable substrates to an abundant intestinal flora normally present only in the colon, identifying an ideal endogenous hydrogen inducer seems strikingly attractive.

Lactulose is a good option worth considering.

\section{Lactulose mediates hydrogen production and is an ideal endogenous hydrogen inducer}

Lactulose is a synthetic sugar used in the treatment of constipation [32] and hepatic encephalopathy. It is a disaccharide formed from one molecule fructose and one molecule of galactose and cannot be absorbed by human bodies but can be digested by bacteria colonizing within the gastrointestinal tract, especially in the colon. One of the main byproducts is hydrogen. Oral administration of lactulose significantly increases hydrogen production [33], which can be detected by hydrogen breath test, introduced several decades ago as a diagnostic test for small bowel bacterial overgrowth [34].

In 2004, it was observed that lactulose had some protective effects on DSS-induced colitis [35]. Interestingly enough, it demonstrated that lactulose reduced the severity of colonic lesions induced by DSS treatment in a dose-dependent manner, the effect at $100 \mathrm{mg} / \mathrm{kg}$ being more potent than that of 5-ASA. Lactulose also prevented the colon shortening and ameliorated the histological inflammation, together with significant attenuation of the increase in MPO activity as well as lipid peroxidation following DSS treatment. Lactulose lowered oxidative stress state. Hydrogen may be the key.

A study showed that $20 \mathrm{~g}$ lactulose administration could increase the exhaled hydrogen nearly to the same level of exhaled hydrogen as compared to the consumption of $300 \mathrm{ml}$ hydrogen-rich saline and had a longer maintenance time of hydrogen concentration [32]. Therefore, oral administration of lactulose may be a better option in terms of maintenance of the appropriate 
hydrogen gas levels in the body. Furthermore, lactulose can treat constipation by increasing the water content and volume of the stools in the bowel, making them softer and easier to pass. As is known, constipation is one of the important risk factors for cerebrovascular accidents and a major complication after stroke.

\section{Hypothesis}

Lactulose has been proved effective in ameliorating oxidative stress injuries in DSS-induced mice colitis. Based on these observations and experiments, we hypothesize that lactulose may be a novel promising preventive and therapeutic option for stroke as an indirect antioxidant. By increasing gastrointestinal tract derived hydrogen, it may significantly reduce the possibility of stroke and alleviate ischemia/reperfusion injury after the stroke, improving the life quality of patients. What's more, it is noteworthy that lactulose probably has many other beneficial antioxidant effects on a wide range of aspects, such as cardiovascular diseases, neurodegenerative diseases et al., which still needs further study.

\section{Author details \\ ${ }^{1}$ Graduates Management Unit, Changhai hospital, Second Military Medical University, Shanghai 200433, PR China. ${ }^{2}$ Graduates Management Unit, Second Military Medical University, Shanghai 200433, PR China. ${ }^{3}$ Department of Diving Medicine, Faculty of Naval Medicine, Second Military Medical University, Shanghai 200433, PR China.}

Received: 12 December 2011 Accepted: 6 February 2012 Published: 6 February 2012

\section{References}

1. Donnan GA, Fisher M, Macleod M, Davis SM: Stroke. Lancet 2008, 371:1612-1623.

2. Soto S, Artaza T, Gomez R, Camacho Fl, Rodriguez I, Gonzalez C, Potenciano JLM, Rodriguez R: Rib metastasis revealing hepatocellular carcinoma. Scand J Gastroenterol 2000, 35:333-336.

3. Murray CJ, Lopez AD: Mortality by cause for eight regions of the world: Global Burden of Disease Study. Lancet 1997, 349:1269-1276.

4. Sims NR, Muyderman H: Mitochondria, oxidative metabolism and cell death in stroke. Biochim Biophys Acta 1802:80-91.

5. Boveris $A$, Chance $B$ : The mitochondrial generation of hydrogen peroxide. General properties and effect of hyperbaric oxygen. Biochem J 1973, 134:707-716.

6. Chan PH: Oxygen radicals in focal cerebral ischemia. Brain Pathol 1994, 4:59-65.

7. Ozkul A, Akyol A, Yenisey C, Arpaci E, Kiylioglu N, Tataroglu C: Oxidative stress in acute ischemic stroke. J Clin Neurosci 2007, 14:1062-1066.

8. Nanetti L, Raffaelli F, Vignini A, Perozzi C, Silvestrini M, Bartolini M, Provinciali L, Mazzanti L: Oxidative stress in ischaemic stroke. Eur J Clin Invest 2011 .

9. Green PS, Simpkins JW: Neuroprotective effects of estrogens: potential mechanisms of action. Int J Dev Neurosci 2000, 18:347-358.

10. Ohsawa I, Ishikawa M, Takahashi K, Watanabe M, Nishimaki K, Yamagata K, Katsura K, Katayama Y, Asoh S, Ohta S: Hydrogen acts as a therapeutic antioxidant by selectively reducing cytotoxic oxygen radicals. Nat Med 2007, 13:688-694.

11. Matchett GA, Fathali N, Hasegawa Y, Jadhav V, Ostrowski RP, Martin RD, Dorotta $\mathrm{IR}$, Sun $\mathrm{X}$, Zhang $\mathrm{JH}$ : Hydrogen gas is ineffective in moderate and severe neonatal hypoxia-ischemia rat models. Brain Res 2009, 1259:90-97.
12. Cai JM, Kang ZM, Liu K, Liu WW, Li RP, Zhang JH, Luo X, Sun XJ: Neuroprotective effects of hydrogen saline in neonatal hypoxia-ischemia rat model. Brain Research 2009, 1256:129-137.

13. Chen CW, Chen QB, Mao YF, Xu SM, Xia CY, Shi XY, Zhang JH, Yuan HB, Sun XJ: Hydrogen-Rich Saline Protects Against Spinal Cord Injury in Rats. Neurochemical Research 2010, 35:1111-1118.

14. Mao YF, Zheng XF, Cai JM, You XM, Deng XM, Zhang JH, Jiang L, Sun XJ: Hydrogen-rich saline reduces lung injury induced by intestinal ischemia/ reperfusion in rats. Biochem Biophys Res Commun 2009, 381:602-605.

15. Chen H, Sun YP, Hu PF, Liu WW, Xiang HG, Li Y, Yan RL, Su N, Ruan CP, Sun XJ, Wang QA: The Effects of Hydrogen-Rich Saline on the Contractile and Structural Changes of Intestine Induced by Ischemia-Reperfusion in Rats. Journal of Surgical Research 2009, 167:316-322.

16. Fukuda Kl, Asoh S, Ishikawa M, Yamamoto Y, Ohsawa I, Ohta S: Inhalation of hydrogen gas suppresses hepatic injury caused by ischemia/ reperfusion through reducing oxidative stress. Biochemical and Biophysical Research Communications 2007, 361:670-674.

17. Hayashida K, Sano M, Ohsawa I, Shinmura K, Tamaki K, Kimura K, Endo J, Katayama T, Kawamura A, Kohsaka S, Makino S, Ohta S, Ogawa S, Fukuda K: Inhalation of hydrogen gas reduces infarct size in the rat model of myocardial ischemia-reperfusion injury. Biochemical and Biophysical Research Communications 2008, 373:30-35.

18. Huang Y, Xie KL, Li JP, Xu N, Gong G, Wang GL, Yu YH, Dong HL, Xiong LZ: Beneficial effects of hydrogen gas against spinal cord ischemiareperfusion injury in rabbits. Brain Research 2010, 1378:125-136.

19. Cai JM, Kang ZM, Liu WW, Luo X, Qiang S, Zhang JH, Ohta SG, Sun XJ, Xu WG, Tao HY, Li RP: Hydrogen therapy reduces apoptosis in neonatal hypoxia-ischemia rat model. Neuroscience Letters 2008, 441:167-172.

20. Domoki F, Olah O, Zimmermann A, Nemeth I, Toth-Szuki V, Hugyecz M, Temesvari P, Bart F: Hydrogen is Neuroprotective and Preserves Cerebrovascular Reactivity in Asphyxiated Newborn Pigs. Pediatric Research 2010, 68:387-392.

21. Ji Q, Hui KL, Zhang LD, Sun XJ, Li WY, Duan ML: The Effect of HydrogenRich Saline on the Brain of Rats with Transient Ischemia. Journal of Surgical Research 2010, 168:E95-E101.

22. Wang C, Li JA, Liu QA, Yang R, Zhang JH, Cao YP, Sun XJ: Hydrogen-rich saline reduces oxidative stress and inflammation by inhibit of JNK and NF-kappa B activation in a rat model of amyloid-beta-induced Alzheimer's disease. Neuroscience Letters 2011, 491:127-132.

23. Fu Y, Ito M, Fujita Y, Ichihara M, Masuda A, Suzuki Y, Maesawa S, Kajita Y, Hirayama M, Ohsawa I, Ohta S, Ohno K: Molecular hydrogen is protective against 6-hydroxydopamine-induced nigrostriatal degeneration in a rat model of Parkinson's disease. Neuroscience Letters 2009, 453:81-85.

24. Fujita K, Seike T, Yutsudo N, Ohno M, Yamada H, Yamaguchi H, Sakumi K, Yamakawa Y, Kido MA, Takaki A, Katafuchi T, Tanaka Y, Nakabeppu Y, Noda M: Hydrogen in Drinking Water Reduces Dopaminergic Neuronal Loss in the 1-methyl-4-phenyl-1,2,3,6-tetrahydropyridine Mouse Model of Parkinson's Disease. Plos One 2009, 4, DOl:e724710.721371/journal. pone. 0007247 .

25. Levitt MD: Production and excretion of hydrogen gas in man. N Engl J Med 1969, 281:122-127.

26. Sobko T, Norman M, Norin E, Gustafsson LE, Lundberg JO: Birth-related increase in intracolonic hydrogen gas and nitric oxide as indicator of host-microbial interactions. Allergy 2005, 60:396-400.

27. Maffei HV, Metz G, Bampoe V, Shiner M, Herman S, Brook CG: Lactose intolerance, detected by the hydrogen breath test, in infants and children with chronic diarrhoea. Arch Dis Child 1977, 52:766-771.

28. Olson JW, Maier RJ: Molecular hydrogen as an energy source for Helicobacter pylori. Science 2002, 298:1788-1790.

29. Suzuki Y, Sano M, Hayashida K, Ohsawa I, Ohta S, Fukuda K: Are the effects of alpha-glucosidase inhibitors on cardiovascular events related to elevated levels of hydrogen gas in the gastrointestinal tract? Febs Letters 2009, 583:2157-2159.

30. Shimouchi A, Nose K, Takaoka M, Hayashi H, Kondo T: Effect of dietary turmeric on breath hydrogen. Dig Dis Sci 2009, 54:1725-1729.

31. Kajiya M, Sato K, Silva MJB, Ouhara K, Do PM, Shanmugam KT, Kawai T: Hydrogen from intestinal bacteria is protective for Concanavalin Ainduced hepatitis. Biochemical and Biophysical Research Communications 2009, 386:316-321.

32. Voskuijl W, de Lorijn F, Verwijs W, Hogeman P, Heijmans J, Makel W, Taminiau J, Benninga M: PEG 3350 (Transipeg) versus lactulose in the 
treatment of childhood functional constipation: a double blind, randomised, controlled, multicentre trial. Gut 2004, 53:1590-1594.

33. Florent C, Flourie B, Leblond A, Rautureau M, Bernier JJ, Rambaud JC: Influence of chronic lactulose ingestion on the colonic metabolism of lactulose in man (an in vivo study). J Clin Invest 1985, 75:608-613.

34. Rhodes JM, Middleton P, Jewell DP: The lactulose hydrogen breath test as a diagnostic test for small-bowel bacterial overgrowth. Scand J Gastroenterol 1979, 14:333-336.

35. Rumi G, Tsubouchi R, Okayama M, Kato S, Mozsik G, Takeuchi K: Protective effect of lactulose on dextran sulfate sodium-induced colonic inflammation in rats. Dig Dis Sci 2004, 49:1466-1472.

doi:10.1186/2045-9912-2-3

Cite this article as: Chen et al: Lactulose: an effective preventive and therapeutic option for ischemic stroke by production of hydrogen. Medical Gas Research 2012 2:3.

\section{Submit your next manuscript to BioMed Central} and take full advantage of:

- Convenient online submission

- Thorough peer review

- No space constraints or color figure charges

- Immediate publication on acceptance

- Inclusion in PubMed, CAS, Scopus and Google Scholar

- Research which is freely available for redistribution

Submit your manuscript at www.biomedcentral.com/submit 